\title{
What Role for "Long-term Insurance" in Adaptation? An Analysis of the Prospects for and Pricing of Multi-year Insurance Contracts
}

\author{
Trevor Maynard ${ }^{\mathrm{a}}$ and Nicola Ranger ${ }^{\mathrm{b}}$ \\ ${ }^{a}$ Lloyd's, One Lime Street, London EC3M 7HA, U.K. \\ E-mail: Trevor.maynard@lloyds.com \\ ${ }^{\mathrm{b}}$ Grantham Research Institute on Climate Change and the Environment, London School of Economics and \\ Political Science, Houghton Street, London WC2A 2AE, U.K.
}

Multi-year insurance has been proposed as a tool to incentivise policy-holders to invest in property-level adaptation. In a world of rising natural catastrophe risks, such autonomous adaptations could have significant benefits for the property owner, the insurer and society. We review some arguments made in respect of multi-year contracts and provide new analyses on their price implications. We conclude that even under conditions of known and stationary risk, initial capital requirements could be around 50 per cent higher for a 10 -year contract than an annual contract and the annual premium around 5.5 per cent higher; in the real world of changing and uncertain risks, premiums would be even higher. We also conclude that multi-year contracts have several additional disadvantages that are likely to limit their demand and availability in the general retail insurance market. For adaptation, we conclude that other tools, such as risk-based premiums and loans for adaptation tied to the property, have greater potential.

The Geneva Papers (2012) 37, 318-339. doi:10.1057/gpp.2012.10

Keywords: insurance economics; climate change; multi-year insurance contracts; long-term insurance; adaptation; risk reduction

\section{Introduction}

Over the past three decades, global economic losses from weather-related events have increased at a rate of U.S.\$2.7 billion per year in real terms; that is, a tripling of annual damages over the period. ${ }^{1}$ Several studies have shown that this increase has been mainly driven by an increasing exposure to disasters ${ }^{2}$; driven by population growth, increased wealth and an accumulation of people and assets in regions more exposed to weather catastrophes. These trends are expected to continue in the future, but also be aggravated by an increase in the intensity of weather events globally

\footnotetext{
${ }^{1}$ Neumayer and Barthel (2011).

${ }^{2}$ For example Neumayer and Barthel, 2011 global analyses and Pielke and Landsea, 1998 for U.S. hurricane losses.
} 
(on average) as a result of man-made climate change. ${ }^{3}$ Some past authors have described the confluence of these pressures as a new era of catastrophes. ${ }^{4}$

Managing risks from natural disasters in a world of increasing population, wealth and climate change will require greater action to reduce vulnerability at the local level. This includes better managing exposure to natural hazards, through urban and landuse planning, as well as enhancing societal resilience and resistance and reducing individual vulnerability. In many hazard-prone regions, there is evidence that property owners under-invest in property-level risk reduction measures. ${ }^{5}$ In a world of rising levels of risk from natural hazards, closing this investment gap would have significant benefits not only for property owners, but also insurers and society as a whole. This paper discusses the use of insurance as an economic instrument to incentivise autonomous adaptation. Previous authors have suggested that insurance can be a powerful tool in this respect as the price and availability of insurance communicates a signal of the level of risk to the insured. ${ }^{6}$ In principle this should encourage the insured to take cost-effective measures to reduce risk.

A number of authors have demonstrated that the insurance industry itself can benefit from doing more to incentivise risk reduction. Unhindered climate change and an increased concentration of insured assets in exposed regions are likely to increase the correlation and volatility of losses to levels that could have profound effects on the insurability of natural hazard risks and the affordability of insurance. ${ }^{7}$ The consequent public and political discontent could have knock-on effects for other lines of business, as observed, for example, in the Florida insurance market.

There are several ways in which the insurance industry can help bring about improved individual and societal risk management. ${ }^{8}$ This paper focuses on the arguments for and against one proposed insurance tool, the introduction of multi-year insurance contracts alongside risk-based insurance pricing. ${ }^{9}$ It has been suggested that multi-year contracts, otherwise known as "long-term insurance", which provide a guaranteed price (or guaranteed ceiling and floor price) over a term from 3 to as much as 25 years, could have significant benefits for adaptation by providing greater incentives for the insured to invest in cost-effective property-level resistance and resilience measures.

While multi-year contracts are not unheard of in the insurance market today, particularly in commercial insurance lines and for high net-wealth individuals, they are rare in the majority of general retail insurance markets. ${ }^{10}$ Where they do exist in the commercial and high net-wealth markets, the policy term is typically no more than 3 years.

\footnotetext{
${ }^{3}$ IPCC (2007).

${ }^{4}$ Kunreuther et al. (2009).

${ }^{5}$ Kunreuther et al. (1978); Kunreuther (1996); Cabinet Office (2008).

${ }^{6}$ For example Maynard (2008); The Geneva Association (2009); Herweijer et al. (2009); Kunreuther et al. (2009).

${ }^{7}$ For example Mills (2005); Lloyd's of London (2006); CII (2009); Herweijer et al. (2009).

${ }^{8}$ Ward et al. (2008); Herweijer et al. (2009).

${ }^{9}$ Jaffee et al. (2008); Kunreuther et al. (2009).

${ }^{10}$ Goss and O’Neill (2010).
} 
320

In the following sections, we review the arguments for and against multi-year insurance contracts from different perspectives. The following section examines the case for multi-year insurance contracts given in the academic literature. The section after that provides new quantitative analyses on the implications for the technical price of insurance. The two subsequent sections consider the broader issues of practicality and trade-offs. The paper focuses exclusively on P\&C insurance contracts and mainly for general retail insurance provided by the private insurance sector; however, some lessons learned from the life insurance sector are included to illustrate how long-term guarantees have proved hard to manage in practice. Applications to the commercial market and public insurance providers will be discussed in the "Discussion" section.

\section{The case for multi-year contracts}

Kunreuther ${ }^{11}$ identifies a number of important barriers to individual action to reduce risk at the property-level: financial constraints (upfront costs); lack of information or poor use of information in decision-making; a perception that the government will provide support in the event of a disaster; unawareness or misperception of the true risk they face; and other behavioural issues, in particular short-termism. ${ }^{12}$ Kunreuther et al. ${ }^{4}$ suggest that risk-based insurance premiums can be an important tool to help overcome these barriers. The premise is that if the premium reflected the level of risk, and the insurer accordingly offered a risk-appropriate discount to homeowners who invest in loss reduction, this would provide an economic incentive to a property owner to reduce risk to the costeffective level. ${ }^{13}$ Effectively they argue that moral hazard will be reduced through incentivising risk mitigation. Similarly, an individual moving into a high risk area would be more aware of the risk and could act accordingly. However, in the real world, the price of a contract rarely reflects the true level of risk, particularly in the case of homeowner (or general retail) insurance. The impact of incentives ${ }^{14}$ on insurance demand through reducing moral hazard is an open question for further research.

In practice, even with risk-based premiums in place, this economic incentive is not sufficient to overcome all the observed barriers to action. ${ }^{11}$ For example, the technical premium reduction with risk reduction is often quite small compared with the upfront cost of the mitigation measure ${ }^{15}$ and therefore, the economic incentive is relatively weak. In addition, Goss and O'Neill ${ }^{10}$ suggest that the incentive is further weakened because risk reduction investments do not tend to be reflected in property values, meaning that the benefit is lost if the individual sells the property. Kunreuther et al. ${ }^{4}$

${ }^{11}$ Kunreuther (1996).

${ }^{12}$ Studies have shown that individuals tend to focus on the returns only over the next couple of years. There is also evidence to suggest that temporally distant payoffs are disproportionally discounted relative to immediate ones (e.g. see Kunreuther and Michel-Kerjan, 2009 and references therein).

${ }^{13}$ To illustrate this, consider a simplified example. Assume that a homeowner's insurance premium is priced at $\$ 100$ per annum, equal to the level of average annual loss. Then if the homeowner could invest in a risk reduction measure at a cost of \$200 that would reduce the Anual Average Loss to her property by 25 per cent, the investment would pay back after 8 years.

14 Eisen (1990).

${ }^{15}$ Kunreuther (2005). 
make several recommendations that aim to help overcome these barriers. For example, they suggest that loans should be provided to property-owners (from public schemes or other initiatives) to help spread the upfront investment costs over time (overcoming the financial barrier); if the annual rate of repayment were smaller than the annual insurance premium discount gained as a result then the property-owner would see an immediate financial benefit from the investment and so a strong incentive to take action. Further, if loans were tied to the property, rather than the individual, this would overcome the disincentive created by the prospect of moving house.

Kunreuther et al. ${ }^{4}$ argue that this strategy works only if the property-owner could be assured that the insurer would continue to provide the premium discount. Hence, they recommend the use of a multi-year insurance contract with a guaranteed price and discount. They argue that the multi-year contract, with transparent pricing, could also strengthen the economic incentive by making the benefits of the investment in risk reduction more visible upfront. ${ }^{16}$ Additional benefits of a multi-year contract given by Kunreuther and Michel-Kerjan ${ }^{17}$ include the following:

- A multi-year contract at a guaranteed price (or alternatively, a price with predefined ceiling and floor) provides financial certainty for the policy-holder and a guarantee of insurance coverage over the policy term.

- Multi-year contracts could decrease the transaction or search costs to policy-holders in a case where annual policies are not renewed by their insurer (though search costs may increase per policy as multi-year contracts mean more complex decisions).

- Multi-year contracts could reduce administrative costs for the insurer and increase certainty by reducing the turnover of customers.

- Multi-year contracts could encourage a higher degree of insurance coverage across society with benefits to individuals and society as a whole. For example, in some markets, policy-holders tend to cancel or not renew contracts if no losses have occurred and this can leave them, and society, more exposed when an event occurs.

Goss and O'Neill ${ }^{10}$ suggest that multi-year contracts could also increase the incentive for the insurer itself to invest in improving the resistance and resilience of its insured properties. Today, insurers have little incentive to reinstate a property in a more resilient and resistant manner as this tends to be more expensive and the investing insurer is not guaranteed to benefit as the policy-holder may switch to another insurer. ${ }^{18} \mathrm{~A}$ more long-term relationship between the insurer and policyholder would help to alleviate this barrier by allowing the insurer to offset the investment costs against future reductions in losses to the property. ${ }^{19}$

${ }^{16}$ For example, rather than a $\$ 35$ premium discount each year in an annual contract, which seems small compared to an upfront investment of $\$ 250$, the insured would see a guaranteed $\$ 350$ total premium discount over a 10 -year contract.

${ }^{17}$ Kunreuther and Michel-Kerjan (2009).

18 Boyer and Gobert (2008).

19 The viability of this decision would depend on the case. It is likely that the contract would need to be much longer than 5 years to offset the investment costs. Goss and O'Neill (2010) suggest that the premium would need to be much higher than for a contract without resilient reinstatement (e.g. perhaps 40 per cent higher for a 5-year flood insurance contract on a high risk property and greater for a lower risk property). 


\section{Price implications}

The annual premium of a multi-year contract would likely be greater than the premium of an equivalent annual contract. First, the capital requirements and return on capital demanded by investors would be higher. Second, uncertainty and ambiguity is greater. Third, we would expect the expenses associated with the contract to change. In this section, we present a new analysis of the impacts of the capital loading on the premium for a multi-year contract and draw on past studies to discuss expenses and the impact of uncertainty on the premium. It could be argued that the offer of a multiyear policy will then encourage climate adaptation; thereby reducing both expected claims and uncertainty - and hence reducing the multi-year premium (whether this is below the original single year premium would depend on the circumstances). In this case, however, the post-adaptation single year premium would be lower still, as our analysis shows. The policy-holder may still be better off paying for the adaptation and purchasing a cheaper annual policy on a rolling basis. We wish to illustrate in this paper that for a given level of risk the single year premium will be lower.

\section{Capital loading under conditions of known and stationary risk}

The formula to calculate the premium of an insurance contract can be expressed as Eq. (1), where $P$ is the annual premium, $E(C)$ is the annual expected value of claims, $E(X)$ is the annual expected value of expenses and $\alpha \cdot K$ represents the capital loading, where $K$ is the capital requirement and $\alpha$ is the annual return on capital demanded by shareholders.

$$
P=E(C)+E(X)+\alpha \cdot K
$$

To explore the impacts of the length of the policy term of the premium we determine $P$ via stochastic simulation of claims, expenses and an investment process. The method is detailed in the Appendix and assumes that the risk is stationary and known. We impose the condition that the insurer must remain solvent (i.e. premiums plus capital must exceed claims plus expenses) at all times with 99.5 per cent probability (i.e. a 1-in200 year continuous solvency condition).

Figure 1 shows the resulting annual premium for a multi-year contract as a function of the length of the policy term, from 1 to 10 years. The annual premium is shown for two cases: for a constant value of $\alpha$ (set at 10 per cent) and for a value of $\alpha$ that increases with the policy duration (from 10 per cent for a 1-year contract to 12 per cent for a 10-year contract). We suggest that the second case is more realistic as shareholders will demand a higher return on capital for a longer guarantee period. In both cases, the annual premium is shown to increase with the duration of the policy. Figure 1 shows the reason for this increase is that the capital requirement increases with a longer policy term; $K$ is more than 50 per cent higher for a 10 -year contract than an annual contract. The annual premium is around 5.5 per cent higher for a 10 -year contract for increasing $\alpha$.

If the solvency condition is relaxed such that solvency is assessed only at the end of the term, allowing insolvency in between, then this reduces the impact of policy 

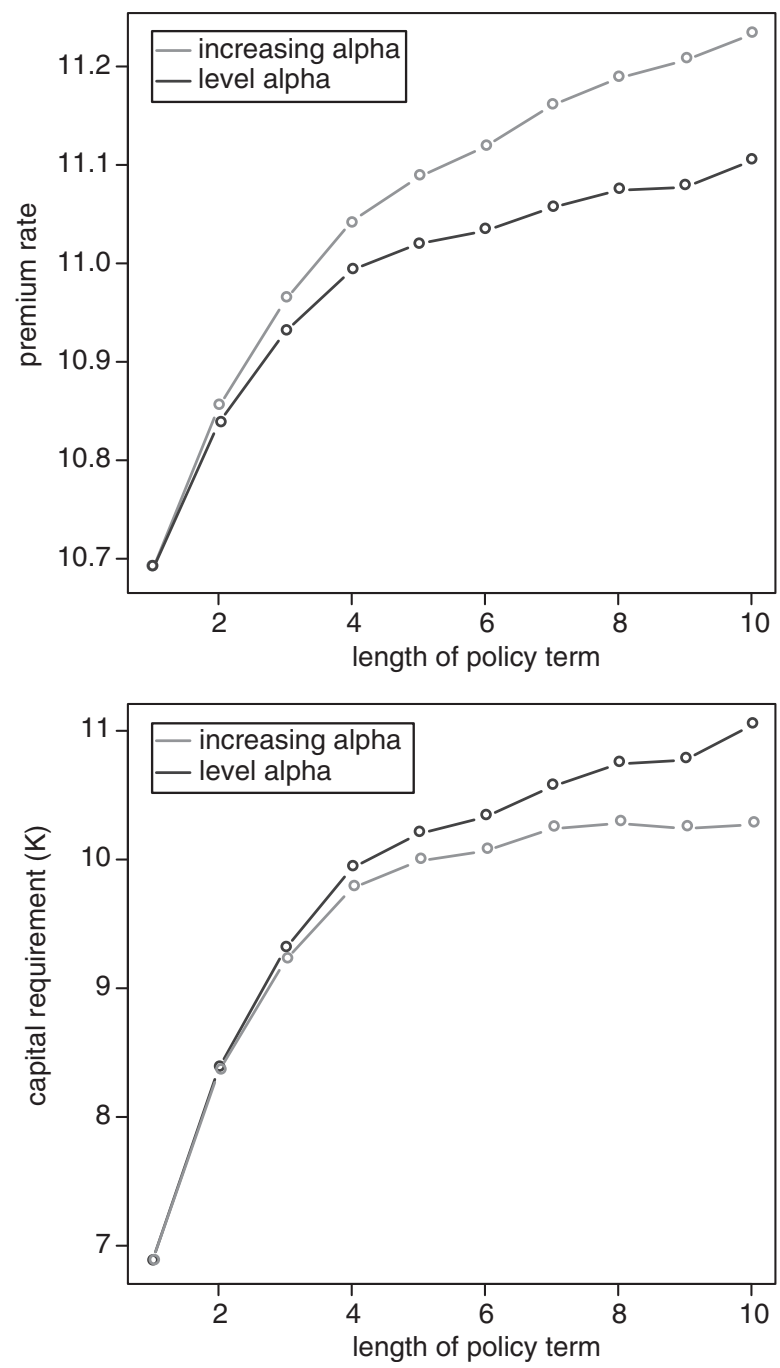

Figure 1. Annual premium (top) and capital requirement (bottom) as a function of the length of the policy term for a multi-year insurance contract.

duration on the premium (Figure 2). This case is equivalent to being able to raise additional capital at a floating rate equivalent to the yield on the asset mix of the company. This would not be realistic for a company in distress. Therefore this hypothetical solvency rule is not likely in a realistic regulatory regime. This is discussed further in the Appendix. This example is shown for comparison with the analysis in Figure 3. With the more relaxed solvency condition, the annual premium plateaus at a duration of around 5 years and falls gradually beyond around 8 years. At the plateau, capital requirements remain around 30 per cent higher than for an annual contract. 

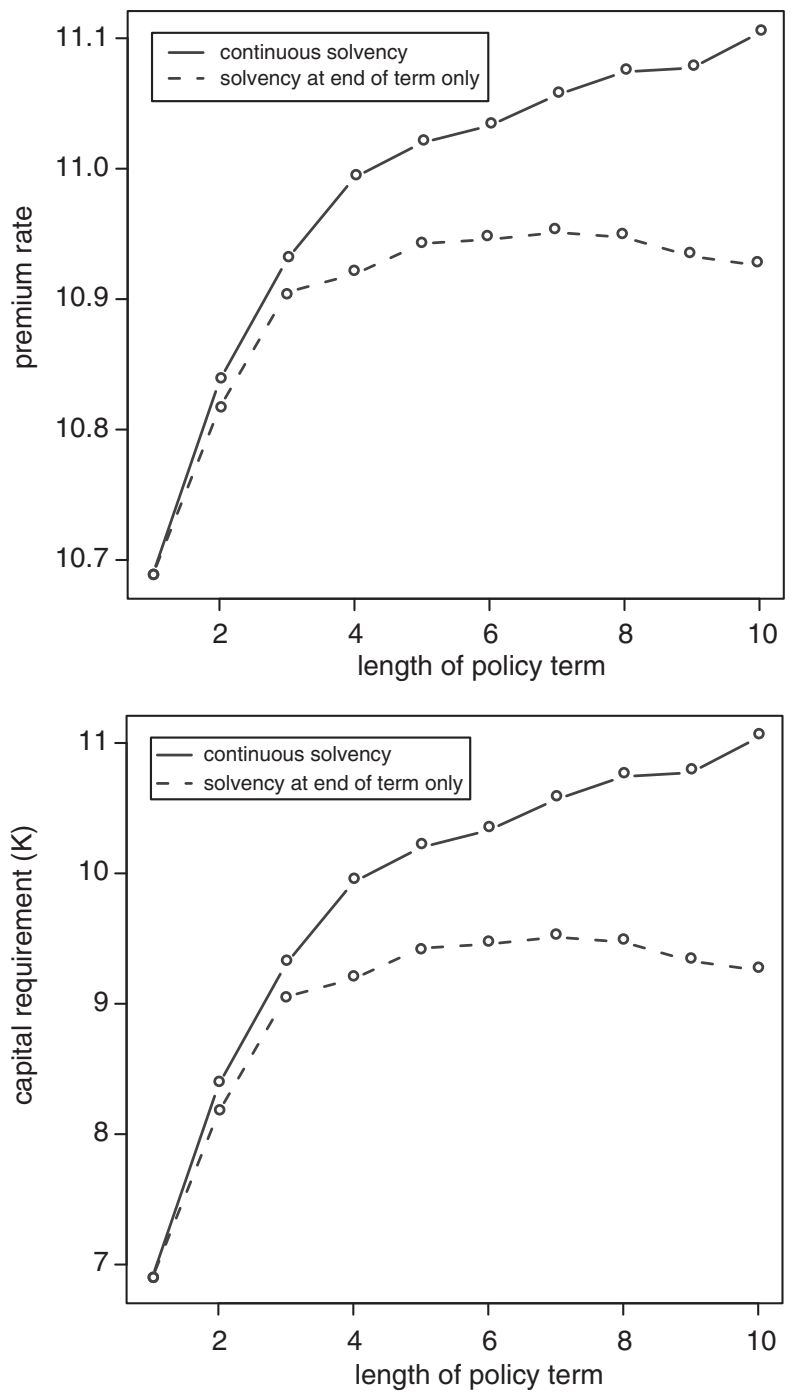

Figure 2. Annual premium (top) and capital requirement (bottom) as a function of the policy duration under conditions of continuous solvency (solid) and solvency at the end of the policy term (dashed) for constant $\alpha$.

Capital requirements are higher for a multi-year contract because the insurer must hold additional capital to cover the possibility that multiple claims are paid over the policy duration. This is illustrated in Figure 3, which shows a simplified simulation representing the ratio of claims and expenses paid to the sum of the total premium income and investment return, ignoring profit margins, against time (in years); this is effectively the inverse of the combined ratio with investment return. If no capital were held, a value less than 1 on the $y$-axis would imply that the insurer has become insolvent; that is, the sum of claims and expenses has exceeded accumulated premium 


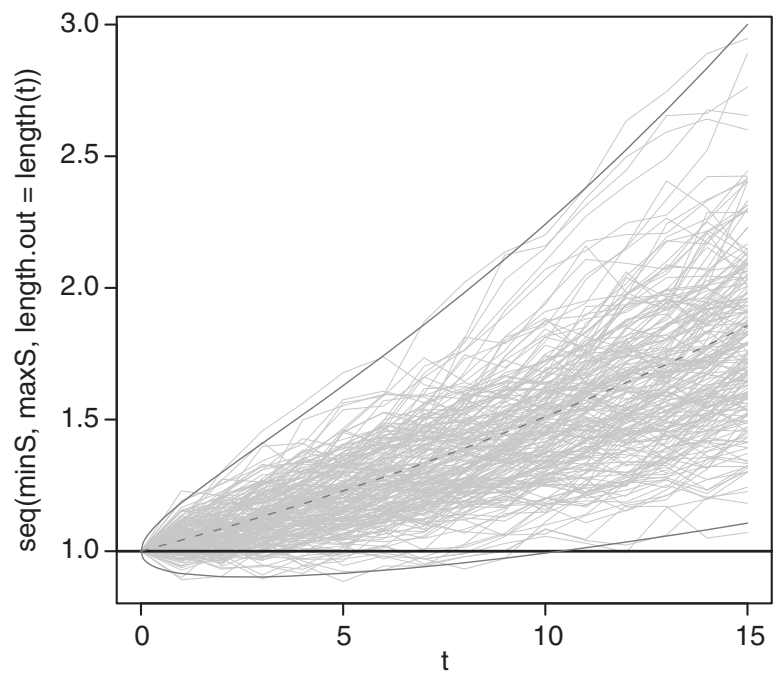

Figure 3. Stochastic simulation to illustrate the solvency process. The simulation represents the ratio of claims to the accumulated premium plus capital ( $y$-axis) vs. time in years ( $x$-axis). The grey lines are individual simulations, the dashed line shows the expected values and the solid lines bound the $5^{\text {th }}$ and $95^{\text {th }}$ percentiles. Simulations with a y-value less than 1 can be interpreted as insolvent.

income. The simulation is stochastic ${ }^{20}$; individual simulation runs are shown in grey and the $5^{\text {th }}$ and $95^{\text {th }}$ percentiles are bounded by solid lines indicating a "solvency envelope" where the solvency criteria is hypothetically set at a 95 per cent Value at Risk. The further the envelope is below 1 the more capital a company would need to remain solvent with 95 per cent confidence up to that term. The simulation demonstrates that the capital initially increases as the policy term increases and reaches a peak at around 2-3 years. The required capital then declines and becomes negligible after about 10 years, in this simple example.

This simple example can explain our findings in the more complex premium model under the condition of solvency at the end of the term (i.e. where claims can be paid from the total accumulated premium plus initial capital at the end of the term). It demonstrates that for shorter length contracts, around 2-5 years, there is a higher chance that total accumulated premium over the policy duration is not adequate to pay claims and maintain solvency, and therefore more capital must be held initially to ensure that the solvency condition is met. From Figure 2, the most rapid increases in capital requirements occur between year 1 and year 3. For a policy term of beyond around $8-10$ years, the total premium accumulated over the policy duration is more than adequate to pay claims and maintain solvency with the required probability (95 per cent) so the initial capitalisation can be reduced. We stress this simple example only tests solvency at the end of the policy term, where mid-term losses can be

${ }^{20}$ The process shown in Figure 3 is a simple geometric Brownian motion process defined by $X_{t}=e^{\mu+\sigma W_{t}}$ where $\mu=0.04, \sigma=0.05$ and $W_{t}$ is a Weiner process with zero mean and unit variance. 
recouped from future premiums. Under the more conservative (and realistic) condition of continuous solvency (Figure 1) we do not observe a plateau and decline in capitalisation requirements because any claims must be covered by the premium accumulated up to the point of the claim plus initial capital, rather than the premium accumulated over the entire policy duration, so the initial capitalisation must be higher.

The simulations presented in this section are for only one policy. In reality, a (re)insurer will be able to diversify risks across a broad portfolio of policies, lines of business and regions. However, we do not believe that this would change the fundamental conclusion of our simulation that the annual cost of a multi-year contract would be higher than an equivalent annual contract. Kreps ${ }^{21}$ suggests that the (re)insurer should require a rate of return on the marginal amount of capital required by the new policy. Where the new policy is correlated with the existing portfolio, our model is adequate. If the new policy were a new class of business or in a region that is not correlated with the existing portfolio then the additional capital required may be smaller, but still greater than that for an equivalent annual contract.

\section{Expenses associated with a multi-year contract}

It is not clear how the longer policy term of a multi-year contract would affect the expenses of the contract; that is $E(X)$ in Eq. (1). The turnover of clients should be lower and therefore, marketing costs should be reduced. The administrative costs could be smaller as the contract is renewed less often; however, interviews with insurers reported in Goss and O'Neill ${ }^{10}$ suggest that this decrease will be marginal as insurers would still need to communicate annually with policy-holders and regularly review risk levels. In addition, Goss and O'Neill suggest that providing multi-year insurance could entail a number of additional start-up costs that would need to be recouped through premiums and they argue that the sale of multi-year contracts would require greater interaction with the salesperson to appropriately assess risk, explain conditions and reduce the scope for mis-buying, increasing the administrative costs per policy.

\section{The impact of uncertainty on premiums}

The largest contribution to the increase in premiums for a multi-year contract is likely to come from the increased uncertainty in each of the elements of Eq. (1) with the length of policy term. Kunreuther et al. ${ }^{22}$ demonstrate that the premium of any insurance contract will be higher under conditions of uncertain or ambiguous risks and Jaffee et $a .^{23}$ demonstrate that an insurer's aversion to ambiguity increases significantly with the policy term. While the pricing of annual contracts will also be subject to uncertainty, it will be greater for a multi-year contract as risk and policy conditions may change over time in ways that are difficult to predict. Where the premium of a multi-year contract is guaranteed, an insurer would need to anticipate changing levels of risk and conditions and price these into the contract from the start.

\footnotetext{
${ }^{21}$ Kreps (1990).

${ }^{22}$ Kunreuther et al. (1995).

${ }^{23}$ Jaffee et al. (2008).
} 
There are several drivers of changes in risk over time. Aerts and Botzen ${ }^{24}$ explored two potential drivers, the impact of climate change and socio-economic development. Their analysis focused on the component $E(C)$ of the premium for a multi-year contract, for the case of flood insurance in the Netherlands. They demonstrate that changes in risk could lead to significant, but uncertain, underestimation of $E(C)$ of up to around 80 per cent for a 5-year contract and 140 per cent for a 15-year contract when compared with the stationary risk assumption. As uncertainty increases over time, the premium would be higher for a longer policy term. In addition, for a longer contract, there will be greater uncertainty over vulnerability (including policy-holder or local government actions to reduce vulnerability), repair costs, regulatory and legal $^{25}$ regimes (which lead to higher than expected expenses or claims), taxation changes, and the price and availability of capital and reinsurance. The trends are difficult to anticipate and adequately price. Capital will need to be held against all these contingencies and the higher ambiguity over such long-term changes in risk and the conditions for insurance will mean that shareholders demand a high return on capital to compensate for the considerable risk. Each of these factors will increase the capital loading of the premium, making it greater than is suggested by our analysis with known and stationary risk.

\section{Disadvantages of multi-year contracts}

\section{Higher premiums and lower flexibility for policy-holders}

The higher price of a multi-year contract (section "Price implications") means that for the policy-holder there is an advantage of a shorter policy term. Indeed, in the survey carried out by the Association of British Insurers (ABI) in 2009, of the 43 per cent of respondents that were interested in multi-year contracts, 97 per cent felt that the price of a multi-year contract should be less than or equal to that of an annual contract. ${ }^{10}$ The ABI survey found that many respondents were concerned about the possible disadvantages of multi-year contracts. The advantage of an annual contract for the policy-holder is that it provides flexibility and choice; the option to renew or renegotiate a contract, or switch to an alternative insurer, to ensure that they get the best price and conditions for insurance. This must be weighed against the disadvantage that prices may fluctuate over time, as well as the potential higher search costs if a policy is cancelled by the insurer.

\section{Lower flexibility for the insurer and less efficient use of capital}

For the insurer, a multi-year contract has the advantage of limiting turnover in policy-holders, but also limits the ability of the insurer to renegotiate the contract or cancel in response to changing conditions or new information; this could mean

\footnotetext{
${ }^{24}$ Aerts and Botzen (2011).

${ }^{25}$ For example, court judgements sometimes re-interpret the risk landscape deciding that claims that were not thought to be covered by the insurance industry should be paid.
} 
greater liability, but also an increase in moral hazard. The additional moral hazard arises because the insured need no longer keep their property in an insurable condition on an annual basis because they have secured insurance over a multi-year time frame- this further increases the risk to the insurer. In addition, the flexibility to raise premiums if necessary after a disaster is an important "pressure valve" for the insurance markets. The insurance industry is arguably an oligopoly and hence major companies are price makers rather than takers. Therefore it is possible for the premium to rise in this way provided sufficiently many companies simultaneously (and independently) agree the need. This phenomenon has been observed many times in practice and does not imply cartel behaviour, simply well-run businesses reacting appropriately to new information. Recent examples of this occurred after the World Trade Center attacks and after hurricanes Katrina, Rita and Wilma. For the insurer it is an important way to rebuild their balance sheet. ${ }^{26}$ Without this pressure value, more capital would need to be held in the first instance and premiums would need to be set higher. This not only implies a higher premium but also a less efficient use of capital and associated opportunity costs to the insurer. ${ }^{27}$ In reality, the inability to rebuild the balance sheet in the event of a significant loss is likely to be seen by private insurers as a severe impediment to offering multi-year contracts. Goss and O'Neill also report concerns of the European Commission that multi-year contracts have historically hindered competition and created a barrier to new entrants in the market, increasing premium costs.

\section{Long-term guarantees and the risk of insolvency}

In the section "Disadvantages of multi-year contracts" we assume that the insurer is able to adequately foresee changing risks and conditions and price this into the premium at the start of the contract. However, as history has shown, our ability to predict the future is limited. For the insurer, the likelihood and impact associated with mispricing a policy are larger than for an annual contract, where premiums can be adjusted each year in response to new information. New information almost always arises after each major catastrophe with the addition of another data point to a very sparse data set. Engineering expectations are tested, hazard behaviour is observed; all catastrophes are unique. In extreme cases, large-scale mispricing could lead to insolvency and on a smaller-scale a less efficient use of capital.

An example of this has already been played out in the U.K. life assurance industry. In the U.K., life assurance companies write long-term business. While this is not related to climate change adaptation or the general insurance markets we believe the lessons learned from this closely related industry, about how hard

${ }^{26}$ The reason for the premium increase after a disaster is that in these circumstances the availability of capital is often restricted and higher rates of return on capital are demanded from investors, increasing the cost of providing insurance coverage. The converse of this is that premium rates typically fall after a number of benign years.

${ }^{27}$ In the case of an under-pricing of contracts, the insurer would be forced to seek additional capital to cover liabilities at higher cost; whereas for over-pricing of contracts, the insurer would see an opportunity cost from holding too higher reserves. 
Table 1 Long-term guarantees implied by three life assurance products

\begin{tabular}{lll}
\hline Product & Description & Effective guarantees \\
\hline Life annuities & $\begin{array}{l}\text { Provide regular payments until the death } \\
\text { of the insured. }\end{array}$ & $\begin{array}{l}\text { Interest rates until death } \\
\text { Average policy-holder mortality }\end{array}$ \\
$\begin{array}{l}\text { Pensions savings with } \\
\text { guaranteed annuity rates }\end{array}$ & $\begin{array}{l}\text { Provide a specific conversion rate from } \\
\text { accumulated savings into annuity rates. }\end{array}$ & $\begin{array}{l}\text { Spot interest rates years ahead } \\
\text { Future expenses levels } \\
\text { Mortality rates at retirement }\end{array}$ \\
With-profits policies & $\begin{array}{l}\text { Companies offering these products take } \\
\text { regular savings (or lump sums) and } \\
\text { invest them. The policy-holder receives a } \\
\text { guarantee no drop in value and } \\
\text { guaranteed regular bonuses. }\end{array}$ & Investment market fluctuations \\
\hline
\end{tabular}

multi-year guarantees are to price and manage, are highly relevant. We consider three of their products that offer considerable guarantees over the long term: life annuities, pensions savings with guaranteed annuity rates and with-profits policies (Table 1). In the 1970s, 1980s and early 1990s when many of these policies were written, interest rates were often in the double figures, mortality rates were considerably higher and regulation was less onerous so expenses were lower. At the time insurers believed they were making good decisions, anticipating the risks and pricing policies accordingly. However, this assumption proved to be false; interest rates have fallen considerably ${ }^{28}$ (from long-term rates of around 15 per cent p.a. at the start of the 1990 s to 0.5 per cent p.a. in early 2011), mortality rates have gradually improved due to new medicines, changes in diet and a reduction in smoking (the U.K. Office of National Statistics estimates that over the past 30 years, age-standardised mortality rates have declined by 49 and 41 per cent for men and women, respectively), and regulation has tightened leading to greater expenses. When the guaranteed annuity rates started to bite it cost the U.K. life assurance industry tens of billions of pounds to set up the required realistic reserves and this was one of the drivers of the financial difficulties suffered by the firm, Equitable Life, the U.K.'s oldest life assurance company.

As in the life assurance case, a multi-year property insurance is effectively providing a guarantee against interest rate changes, capital market fluctuations, changes in expenses (e.g. due to regulation) and other regulatory changes. A multi-year policy with guaranteed premium has no opportunity to adapt to the changing nature of risk. Difficulties in anticipating the future means it will be probable that polices are underor over-priced as a consequence. Arguably, anticipation of changing risk is even more complex for property insurance than it was for the U.K. life assurance market with the

\footnotetext{
${ }^{28}$ Although some of the interest rate risk was reduced significantly with close matching of asset cash flows with those of liabilities there remained a material level of risk.
} 
330

additional challenges of climate change, natural climate shifts, trends in exposure and shifting vulnerabilities to natural hazards. A more likely outcome is that in a competitive market and under uncertainty, insurers would tend to restrict policies to shorter durations. ${ }^{29}$

Given these risks associated with fixed premiums, a multi-year contract with variable premium might be a more desirable prospect for the insurance industry. ${ }^{30}$ This would also help to reduce the price differential between annual and multi-year contracts and so make them more competitive on the market. Kunreuther et al. ${ }^{4}$ propose that prices be renegotiated over time based on new information, for example based on a regularly monitored risk index arbitrated by a third party. However, such a system would bring considerable technical challenges. Aerts and Botzen ${ }^{24}$ highlight the difficulties in developing such a risk index for natural hazards, given gaps in data availability (e.g. up-to-date risk maps, reflecting changes in protective infrastructure) and the challenges in disentangling trends in risk from statistical noise (e.g. due to chaotic weather) and short-term risk variations (e.g. climate cycles, such as the El Nino Southern Oscillation). Indices would also need to reflect changes in broader conditions, such as the cost of capital and insured asset values. We argue that allowing premiums to adjust each year, even within a defined range, removes some of the benefit of a multi-year contract, in particular, the financial stability created for the policy-holder and the benefit of reduced administrative costs for the insurer. The option to vary the premium would likely need to be accompanied by a right to cancel, removing the security of the long-term relationship between the insurer and policyholder.

\section{Practical challenges for adaptation}

\section{Challenges of risk-based pricing and premium discounts}

Without risk-based premiums, and associated premium discounts for risk reduction, multi-year contracts will not provide an appropriate incentive to reduce risk. However, risk-based premiums are rare in the general retail insurance market and this reflects a number of operational challenges. First, in some markets, such as in a number of the U.S. Gulf States, premiums are artificially suppressed by price regulation or subsidy programmes. ${ }^{31}$ Hence, the success of insurance pricing as an economic tool for adaptation relies on removing any regulation that places upper limits on the price of insurance. ${ }^{17}$ However, although in aggregate insurers must cover their risks, even in markets with competitive pricing (e.g. most of Europe), premiums rarely reflect individual risk in all cases. There is a history of cross-subsidisation of premiums across

${ }^{29}$ Jaffee et al. (2008) suggest that this problem for insurers may be lessened if reinsurers were to provide multi-year contracts. They give the example of catastrophe bonds, which tend to have a maturity of around 3 years. However, it seems likely that reinsurers would face the same disadvantages and impediments to providing multi-year (re)insurance and so transferring the risks up the insurance chain would be unlikely to increase the feasibility of the concept.

${ }^{30}$ Goss and O'Neill (2010); Aerts and Botzen (2011).

${ }^{31}$ Klein (2008); Grace and Klein (2009). 
regions and lines of business, as a result of a culture of solidarity, the nature of traditional bundling of different hazards in a contract, or as a commercial strategy to extend the market by increasing affordability. Where natural catastrophe risk is underpriced, insurers are understandably reluctant to offer discounts to those undertaking cost-effective risk reduction measures.

There are also technical barriers to risk-based pricing and premium discounts for risk reduction. The level of risk faced by a property is site- and building-specific, particularly for hazards such as flooding. In insurance pricing today, typically generalisations are made for local areas and types of buildings to approximate the level of risk. This is sufficient given that the risks (and therefore, uncertainties) are well diversified. However, to provide appropriate economic incentives, premiums would need to more accurately reflect risk and in particular, the reduction in risk associated with investments in property-level resistance and resilience. For this, the underwriting process would require a higher degree of information and the administrative costs of the policy would rise accordingly. A particular concern is the need for on-site verification of the level of protection. Regular validation would be required, perhaps by a third party, to confirm that protection measures were present and adequately maintained. In a competitive market, such products could look unattractive compared to cheaper annual contracts. ${ }^{32}$ From an insurer perspective, offering such policies would increase uncertainty in a portfolio, particularly in the early years until experience is gained.

\section{Mismatch between payback periods and contract duration}

To incentivise risk reduction, a longer contract (and tied to a long-term loan) is more beneficial as the payback period for property-level risk reduction through an insurance premium discount would be often in excess of 5-10 years. To give a simple example, a recent study found that replacing the wall plaster of a property with a water resistant material to improve flood resilience would cost around $£ 2,900$ (if installed during repair) and have a payback of $£ 3,400$ in the event of an extreme flood. ${ }^{33}$ If we assume the probably of an extreme flood were around 1-in-10 (that is, a highly hazard-prone region) then this would amount to a reduction in the technical risk premium of around $£ 340$ per year; hence a payback period of 8.5 years. In a lower (but still high) risk region, where the probability of an extreme flood was 1-in-30 years, the payback period would be 25.5 years. To provide a strong incentive, the insurance contract would need to be at least as long as the payback period. But, empirical evidence suggests a limit on the term of a multi-year contract of around 5 years; ${ }^{10}$ empirical evidence suggests that historically multi-year insurance contract have been enforceable under EU legal systems for up to 5 years, but not beyond and in its 2009 survey, the $\mathrm{ABI}$ found that of those consumers that expressed an interest in multi-year contracts,

\footnotetext{
${ }^{32}$ In the Florida Wind Mitigation Credit scheme, these problems were overcome by making premium discounts mandatory, providing an inspection scheme and regulating the level of price discounts. However, there are suggestions that this scheme has led to distortions in the insurance market (RMS, 2010).

${ }^{33}$ ABI (2009).
} 
around 40 per cent saw 3 years as the maximum desirable policy term and a further 40 per cent gave 5 years. Annual policies could still achieve the premium incentive, however; if adaptation has reduced the risk, then other things equal the premium rate should stay lower.

\section{Discussion}

The previous sections have demonstrated that multi-year contracts have a number of advantages for policy-holders and insurers, but also several disadvantages, in particular, for the private insurer. In a competitive market, these disadvantages are likely to provide an impediment to insurers offering multi-year contracts. The absence of multi-year contracts in the general retail insurance market today suggests that these disadvantages are seen as greater than the benefits of a longer-term relationship between the insurer and the insured.

Kunreuther and Michel-Kerjan ${ }^{17}$ suggest that the wide availability of long-term mortgage contracts provides evidence for the viability of multi-year financial contracts for property-owners. However, we suggest that mortgages provide a poor comparison in this respect. First, typically the repayment rate is floating, allowing the lender to associate rates to changing conditions. Where fixed rate deals are available this is often with duration of not more than 5 years in the U.K., though in other parts of the world they can be longer (Germany for example offers 10 year guarantees). In addition, mortgage risks generally decrease over time as the mortgage is repaid; the loan is secured on a property (providing a cushion where the house price exceeds the outstanding loan) with a value expected to increase on average each year; and for fixed rate deals, the lender can hedge their risk. For property insurance, the balance of evidence points towards an increase in risk over time, possibly including sudden jumps, and there is no cushion. Finally, as was demonstrated by the subprime mortgage crisis in 2008, the mortgage business can also yield unanticipated risks and lock-in significant liabilities for the provider. Looking more broadly, the wider financial markets rarely offer products with long-term guarantees and where they do so it is typically only where a counterparty can be found whose own concerns are negatively correlated. One example is put options in the investment market, which give the holder the right to sell an asset for a minimum value and so provide guarantee against market fluctuations. These contracts are often perceived to be expensive and are typically short-term.

Empirical evidence suggests that there may be greater opportunities for multi-year contracts in the commercial insurance business and for high net worth individuals. European Commission ${ }^{34}$ reports that while on average the duration of contracts in the commercial property insurance market was 12 months for EU member states, countries such as Slovenia, Austria, Italy and the Netherlands do have much longer average durations of between 6 and 8 years. Goss and O'Neill ${ }^{10}$ report contracts for high net worth individuals of around 3 years.

\footnotetext{
${ }^{34}$ European Commission (2007).
} 
Purely public insurance schemes, like the U.S. National Flood Insurance Program, may also have greater prospects for multi-year insurance. ${ }^{35}$ Public insurance schemes may have lower capital requirements and so the price differential compared with an annual contract could be lower. In addition, insolvency is less problematic as public schemes may be able to raise additional capital at low cost from taxation and therefore, the risk of future liabilities (e.g. resulting from long-term guarantees under uncertainty) are a smaller concern. In addition, a purely public insurance scheme is not subject to competitive forces on price and multi-year contracts could be offered as standard.

We suggest that a situation where the benefits of multi-year contracts for the private insurer could outweigh the disadvantages might be where there are predictable cycles in the level of risk, such as in regions where hazard levels are determined by the El Nino Southern Oscillation (Jerry Skees, personal communication). Where there is predictability, insurers could be at risk of adverse selection unless prices are changed actively on an annual basis as the policy-holder would buy insurance only when hazard levels are predicted to be high. A multi-year contract could remove this risk in such markets but would rely on the phenomena being highly predictable. We have not considered this issue in any detail.

Kunreuther and Michel-Kerjan ${ }^{17}$ propose multi-year contracts as one of a package of policy and economic tools to incentivise risk reduction. We conclude that in general the proposals made by Kunreuther and Michel-Kerjan could have significant benefits for climate change adaptation; but that these benefits come not from the multi-year insurance contracts themselves, but from the other tools they suggest, including: transparent and risk-based insurance pricing; inexpensive loans for risk reduction tied to the property; the reflection of risk reduction investments in property prices; the removal of the disincentive provided by the expectation of public aid; and improving the awareness of risk and the availability of information. We argue that these tools are more practical and can have much higher value for adaptation.

This set of tools goes well beyond what the insurance industry alone can provide. From this analysis, we conclude that the immediate challenge for the insurance industry then, with the greatest value for adaptation, is to provide transparent, riskbased premiums. The lack of risk-based premiums today is a disincentive for risk reduction. This is no easy task. In particular, there are considerable administrative and technical challenges for insurers in providing risk-appropriate premium discounts for property owners that invest in risk reduction. These challenges would be lessened in the commercial insurance business and insurance for high-net worth individuals; where administrative costs are typically a much smaller fraction of the total premium and so more significant investments can be made in accurate risk estimation. We suggest that to promote autonomous adaptation, a priority for the insurance industry is to explore methods and tools that would facilitate more accurate property-level estimation of risk at lower cost per policy.

${ }^{35}$ Michel-Kerjan and Kunreuther (2011). 


\section{Conclusions}

In this paper we have reviewed the arguments for and against multi-year contracts as a tool for adaptation and have provided new analyses on their price implications. Simple simulations demonstrate that, even under conditions of stationary and known risk, multi-year insurance policies are more expensive than annual policies. In our model, capital requirements are around 50 per cent higher for a 10 -year contract than an annual contract and the annual premium around 5.5 per cent higher. In the real world, additional factors, in particular the ambiguity involved in anticipating long-term risk, would push premiums even higher. In addition to higher prices, we conclude that multi-year contracts have disadvantages that are likely to limit their availability in the general retail insurance market and by private insurers. In extreme cases, the long-term guarantees implied by multi-year contracts suggest a significant risk to the ongoing solvency of insurers. We do not find strong evidence that multi-year contracts alone could provide adequate incentives for risk reduction among property owners, though other tools, such as risk-based pricing and loans tied to the property, have much greater prospects. We conclude that the immediate challenge for the insurance industry then, with the greatest value for adaptation, is to provide transparent, riskbased premiums.

\section{Acknowledgements}

The authors thank Professor Howard Kunreuther and Dr. Erwann Michel-Kerjan for helpful discussions on long-term insurance. Dr. Andreas Tsanakas and Mr. James Orr (FFA) gave many helpful comments that we have attempted to address in this paper. Dr. Ranger gratefully acknowledges the support of her funders, the Grantham Foundation for the Protection of the Environment, the U.K. Economic and Social Research Council and Munich Re.

\section{References}

Association of British Insurers (2009) Resilient Reinstatement: The Costs of Flood Resilient Reinstatement of Domestic Properties, ABI Research Paper. No 14, London.

Cabinet Office (2008) 'Learning the lessons from the 2007 floods: The Pitt review', from http://archive .cabinetoffice.gov.uk/pittreview/thepittreview/final_report.html, accessed 25 August 2011.

Chartered Insurance Institute (2009) 'Coping with climate change: Risks and opportunities for insurers', from http://www.cii.co.uk/ciiimages/public/climatechange/ClimateChangeReportForeword-Summary.pdf, accessed 25 August 2011.

Eisen, R. (1990) 'Problems of equilibria in insurance markets with asymmetric information', in H. Loubergé (ed.) Risk Information and Insurance, Kluwer Academic Publishers, Dordrecht, The Netherlands, pp. 123-141.

European Commission (2007) Sector Inquiry under Article 17 of Regulation (EC) No 1/2003 on Business insurance, (Final Report) (September).

Goss, R. and O'Neill, D. (2010) Long-term retail general insurance: The potential for long-term home insurance contracts in the context of flood risk, ABI Research Paper No. 21, London.

Herweijer, C., Ranger, N. and Ward, R.E. (2009) 'Adaptation to climate change: Threats and opportunities for the insurance industry', The Geneva Papers on Risk and Insurance-Issues and Practice 34: 360-380.

Intergovernmental Panel on Climate Change (IPCC) (2007) Climate Change 2007: The Physical Science Basis. Contribution of Working Group I to the Fourth Assessment Report of the Intergovernmental Panel on Climate Change, in S. Solomon, D. Qin, M. Manning, Z. Chen, M. Marquis, K. B. Averyt, M. Tignor and H.L. Miller (eds.) Cambridge, U.K. and New York USA: Cambridge University Press. 
Jaffee, D., Kunreuther, H. and Michel-Kerjan, E. (2008) Long term insurance (LTI) for addressing catastrophe risk, BER Working Paper Series No. 14210, National Bureau of Economic Research, Cambridge, MA.

Klein, R. (2008) Catastrophe risk and the regulation of property insurance, Working Paper, Georgia State University, Atlanta, Georgia.

Kreps, R.E. (1990) 'Reinsurer risk loads from marginal surplus requirements', Proceedings of Casualty Actuarial Society LXXVII: 196-203.

Kunreuther, H., Ginsberg, R., Miller, L., Sagi, P., Slovic, P., Borkan, B. and Katz, N. (1978) Disaster Insurance Protection: Public Policy Lessons, New York: John Wiley \& Sons.

Kunreuther, H.C. (1996) 'Mitigating disaster losses through insurance', Journal of Risk and Uncertainty 12 : 171-187.

Kunreuther, H.C. and Michel-Kerjan, E.O. (2009) Managing catastrophes through insurance: Challenges and opportunities for reducing future risks, Working Paper 2009-11-30, The Wharton School, University of Pennsylvania, Philadelphia.

Kunreuther, H.C., Meszaros, J., Hogarth, R. and Spranca, M. (1995) 'Ambiguity and underwriter decision processes', Journal of Economic Behaviour and Organization 26: 337-352.

Kunreuther, H.C., Michel-Kerjan, E.O., Doherty, N.A., Grace, M.F., Klein, R.W. and Pauly, M.V. (2009) At War with the Weather: Managing Large-scale Risks in a New Era of Catastrophes, Cambridge, MA: MIT Press.

Lloyd's of London (2006) 'Climate change: Adapt or bust', from http://www.lloyds.com/ /media/Lloyds/ Reports/360\%20Climate\%20reports/FINAL360climatechangereport.pdf, accessed 25 August 2011.

Maynard, T. (2008) 'Climate change: Impacts on insurers and how they can help with adaptation and mitigation', The Geneva Papers on Risk and Insurance - Issues and Practice 33: 140-146.

Michel-Kerjan, E. and Kunreuther, K. (2011) 'Redesigning flood insurance', Science 333: 408-409.

Mills, E. (2005) 'Insurance in a climate of change', Science 309: 1040-1043.

Neumayer, E. and Barthel, F. (2011) 'Normalizing economic loss from natural disasters: A global analysis', Global Environmental Change 21: 13-24.

Pielke Jr., R.A. and Landsea, C.W. (1998) 'Normalized hurricane damages in the United States: 1925-95', Weather and Forecasting 13: 621-631.

Risk Management Solutions (RMS) (2010) Study of Florida's Windstorm Mitigation Credits Assessing the Impact on the Florida Insurance Market, A Report prepared for Florida Legislature (March).

The Geneva Association (2009) 'Kyoto Statement of The Geneva Association', from http://www.genevaassociation .org/PDF/Risk_Management/Kyoto_Statement_signed_2July09.pdf, accessed 25 August 2011.

\section{Appendix}

\section{Capital requirements and premium model}

This Appendix describes the model for calculating the premium of a multi-year contract based on Kreps. ${ }^{21}$

\section{The model framework}

The model represents a stochastic claims process $C$, as well as an expenses process $X$ and investment process $S$, where: $C_{j}$ is the value of claims occurring in year $j ; X_{j}$ is the value of expenses occurring in year $j$; $S_{j}$ is the annual return in investment, that is, the value of one currency unit, invested at the start of year $j$, at the end of year $j$ (n.b. is not a cumulative return).

The pricing formula is given by Eq. (A.1), where $K$ is the capital requirement for the policy and $\alpha$ represents the return on capital demanded by shareholders.

$$
P_{d}=E(C)+E(X)+\alpha \cdot K
$$


Eq. (1) shows that the premium must be equal to the sum of the expected claims and expenses, plus a "capital loading" to produce the required average return on capital for shareholders. To simplify the model, we assume that premiums are paid at the start of year $j$ and the claims and expenses occur immediately afterward.

The stochastic model is used to estimate the capital requirement $K$ based on a solvency condition that $K+P_{d}$ is sufficient to cover the total value claims and expenses over the duration of the policy with a 99.5 per cent probability (i.e. for 199 out of 200 random draws from the distributions of claims $C$, expenses $X$ and investment $\mathrm{S}$ ). The solvency condition must be met in all years of the contract ${ }^{36}$ (in practice it is measured at the end of each year in the model).

Under the formulation of the multi-year contract we are considering the company cannot change the premium rate during the contract term. This provides the policyholder a long-term guarantee of insurability, for a certain price, over the policy term. The shareholder must supply enough capital to ensure the level of protection falls no lower than 1-in-200 over the period of cover. This is to ensure a similar level of protection as a policy-holder buying an annual premium. In the annual premium case there is a 1-in-200 risk of losing some money from insurer default each year. At the end of a year the policy-holder purchases their next year of cover, in so doing they re-set the default risk to 1-in-200. Of course the premium might be purchased from a different insurer and they run the risk that the premium is higher if insurer's perception of risk levels have changed or the cost of capital has increased over the prior year. The fact that in the multi-year case the policy-holder does not bear the premium rate risk but enjoys the same level of prudential protection is precisely why the premium is higher. The fact that shareholders must put up capital that (at least initially) is thought to be appropriate for the whole policy term, with no opportunity to increase premiums in the future, is precisely why the capital must be higher at the start.

We argue above that the policy-holder should enjoy the same level of protection throughout the policy term as they would in a series of annual policies. This is one point of view and others are possible - in some settings an increasing probability of default as the term increases is thought acceptable. An alternative formulation would be to look at the new EU Solvency II approach where the insurer has to ensure they have enough capital to survive a series of deviations between balance sheets. Yet another approach could look at expected policy-holder deficits. While these may lead to differences in the absolute relationship between capital and premium and different premium levels, we do not believe it will change the overall conclusions, that premiums will be higher for multi-year policies. We may consider these alternative approaches in a future paper. However, we take some comfort that the approach in this paper is broadly equal to the approach of the U.K. regulator as regards liability policies where losses emerge over a multi-year period and firms are required to capitalise to ultimate levels of loss - not interim ones.

\footnotetext{
${ }^{36}$ We note that the condition that 1-in-200 year solvency is maintained at all times is slightly different from Solvency II (which requires solvency from balance sheet to balance sheet), but we would not expect this alternative formulation to alter the conclusions.
} 
The model is set up as described below:

The asset share $Q_{n}$ is equal to the accumulation, at the earned investment rate $S_{j}$, of premium (given by Eq. (A.1)) minus claims and expenses at the end of the contract, where $n$ is the policy term:

$$
Q_{n}=\sum_{i=1}^{n}\left\{\left(E(C)+E(X)+\alpha \cdot K-C_{i}-X_{i}\right) * \prod_{j=i}^{n} S_{j}\right\}
$$

Here $i$ is the time at which the cash flows occur and $j$ is the time in which investment return occurs after point $i$.

Eq. (A.2) implies that claims in a given year occur just after the premium is paid. In reality claims can occur at any time during the year. This approach is taken to simplify the formulae but will not materially change the conclusions. If, for example, claims were assumed to occur mid-year on average then the premium formula would be amended by discounting the claim by half a year of investment return. As such the calculated premium would be slightly lower. The additional investment return this produces would flow through into the asset share - and this would also slightly reduce the capital required. The relationship between premium and capital would be very similar, hence we feel justified in keeping the equations simple.

Formula A.2 assumes that the cost of capital margin $(\alpha \mathrm{K})$ is reinvested until the policy matures. In practice (in periods of good claims experience) a portion of this may be considered "earned" and paid to shareholders in dividends. This would be more complex to model and would increase capital requirements still further as any removal of profits reduces the capital buffer. The point we wish to make is that capital requirements for multi-year policies would be significantly higher, we believe we have achieved this goal without the need to increase complexity.

We define $Q_{o}$ to be to discounted value of $Q_{n}$ at the start of the policy term (Eq. (A.3)), so that $Q_{o}$ is negative in cases where the claims and expenses exceed the premiums on average.

$$
Q_{0}=\frac{Q_{n}}{\prod_{j=1}^{n} S_{j}}
$$

$Q_{n}$ and $Q_{0}$ are stochastic quantities. To meet the solvency condition the following must be true: $K+Q_{o}>0$ in 199 out of 200 cases (i.e. random draws). From Eqns. (A.2) and (A.3) this can be expressed as:

$$
K>-\alpha \cdot K \cdot \ddot{a}(n, S)-\sum_{i=1}^{n}\left\{\left(E(C)+E(X)-C_{i}-X_{i}\right) * v(i-1, S)\right\}
$$

Where $v(i-1, S)=\prod_{j=i}^{n} S_{j} / \prod_{j=1}^{n} S_{j}$, the simulation-specific discount factor and $\ddot{a}(n, S)=\sum_{j=1}^{n} v(j-1, S)$, the simulation-specific annuity factor. This equation can be rearranged to give:

$$
K>\frac{-\sum_{i=1}^{n}\left\{\left(E(C)+E(X)-C_{i}-X_{i}\right) * v(i-1, S)\right\}}{1+\alpha \cdot \ddot{a}(n, S)}
$$


Given this formula, the value $K$ is estimated by simulation. To find the 1 -in-200 year solvency level, we could run 10,000 simulations and select the value of $K$ that is the $50^{\text {th }}$ highest. However, this does not ensure continuous solvency, only that the condition is met at the end of the contract period. A closer approximation to continuous solvency is achieved by the following:

We denote the Right Hand Side of Eq. (A.4) as $f(C, X, S, n)$ and then define:

$$
g(C, X, S, n):=\max _{i=1, n} f(C, X, S, i)
$$

Then in each simulation, we calculate $g(C, X, S, n)$ and select the value of $K$ so that it exceeds $g$ in all but the worst 1 out of 200 cases.

\section{Parameters of the stochastic simulation}

We assume a stationary risk scenario (i.e. no climate change or other trends such as claims inflation), with the three stochastic processes represented by distributions

Table A1 Definition of stochastic variables in the example

\begin{tabular}{ll}
\hline Process & Mathematical definition \\
\hline Claims $(C)$ & Lognormal distribution with mean 9 and variance 5 \\
Expenses $(X)$ & Gamma distribution with mean 1 and variance 0.25 \\
Investments $(S)$ & Exponential Brownian motion process with drift 0.04 and volatility 0.03
\end{tabular}

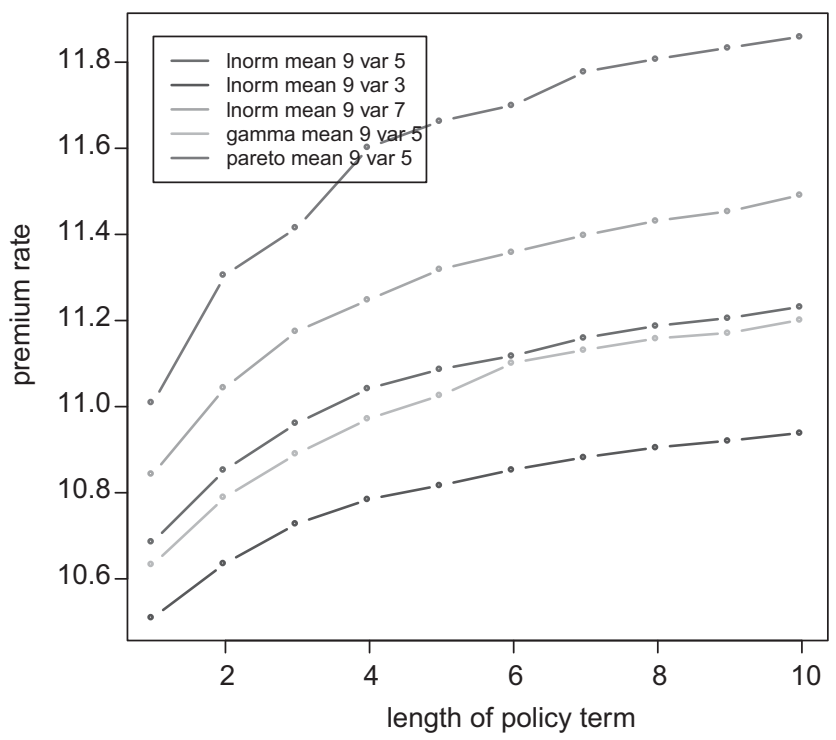

Figure A1. The simulated relationship between premium and length of policy term under different representations of the claims distribution. 
outlined in Table A1. Under this scenario, a sequence of annual policies would have the same premium each year.

Sensitivity tests are also carried out by adjusting the variance (between 3 and 7) and form (lognormal, gamma and pareto) of the claims distribution. We find that adjusting the claims distribution changes the premium but does not change the relationship between the premium and the policy term (Figure A1).

\section{About the Authors}

Trevor Maynard (FIA) is Head of Exposure Management and Reinsurance at Lloyd's. $\mathrm{He}$ is also doing a part time $\mathrm{PhD}$ at the London School of Economics and Political Science (LSE). He is a fellow of the Institute and Faculty of actuaries in the U.K. and has an MSc in pure maths from the University of Warwick. He is interested in the impacts of Climate Change on the insurance industry and the role the industry can play in influencing mitigation and adaptation.

Nicola Ranger is a research fellow and co-lead on Climate Change Adaptation within the Centre for Climate Change Economics and Policy and the Grantham Research Institute on Climate Change and the Environment at the London School of Economics and Political Science (LSE). She is experienced in atmospheric physics, catastrophe risk modelling and climate change policy. Her current research interests include climate-resilient development, the economics of adaptation and the implications of climate change for insurance. 